\title{
Predictors of Stages of Change in Fruit/Vegetable Consumption based on Trans- Theoretical Model: A Population-based Study
}

\author{
Veda Vakili ${ }^{1}$, Majid Khadem-Rezaiyan ${ }^{2 *}$ \\ 1- Department of Community Medicine and Public Health, Faculty of Medicine, Mashhad University of Medical Sciences, Mashhad, Iran. \\ 2- Student Research Committee, Department of Community Medicine and Public Health, Faculty of Medicine, Mashhad University of Medical Sciences, \\ Mashhad, Iran.
}

\section{A B S T R A C T}

Background and Objectives: Low Fruit/Vegetable (FV) diet seems to be a global public health problem. The trans-theoretical stages of change model have long been considered a useful interventional approach in lifestyle modification programs. The aim of this study was to find the most important intermediating factors of FV consumption in Mashhad, Iran.

Materials and Methods: In this cross-sectional design, 777 participants were included with a convenient method from the general population in public places all around the Mashhad City, Iran in 2014. A standardized checklist about socio-demographic characteristics and possible related factors and stages of change questionnaire (6 stages: pre-contemplation, contemplation, preparing, action, maintenance, and termination) were used for data collection. Data were analyzed by SPSS 11.5 software using Chi-square test, Mann-Whitney U test, and Multiple Logistic Regression.

Results: Totally, 254 (47.7\%) and 299 (59.8\%) of participants were in pre-action stages of FV, respectively. Smoking $(\mathrm{OR}=3.2, \mathrm{p}=0.02)$ and believing that this is good for the body $(\mathrm{OR}=0.12, \mathrm{p}=0.001)$ were predictors of the pre-contemplation stage for fruits. Being physically active $(\mathrm{OR}=2, \mathrm{p}=0.008)$, low agreement with health benefits of vegetables $(\mathrm{OR}=8, \mathrm{p}<0.001)$ and low agreement with "vegetables make more diet variability" $(\mathrm{OR}=4, \mathrm{p}<0.005)$ were predictors of pre-contemplation stage for vegetables.

Conclusions: Understanding the pros and cons of changing lifestyle can help public health specialists to perform targeted interventions.

Keywords: Behavior, Fruit, Vegetable, Trans-Theoretical Model, Urban population

\section{Introduction}

Adequate consumption of fruit and vegetable (FV) clearly plays a critical role for human health (1), which could also decrease the risk of many chronic diseases (2-7). Despite many strong recommendations by the World Health Organization (WHO), many individuals have not adopted the minimum recommendations to consume FV. Only in three out of 21 countries (mainly developing countries), FV intake met the minimum WHO recommended consumption (8).

Some studies report the insufficient consumption of FV in elderly in different countries (9-12). Such observations indicate that there is an urgent need for health promotion programs in order to increase FV consumption among this specific age group.

It is obvious that these programs, at least, should be theory-driven if we expect any proper changes in health behaviors (13). Trans-theoretical Model (TTM) is one of the most popular models for studying the behavioral change in health promotion/education programs, and its efficacy has been shown in different studies, especially for FV consumption. According to this model, people progress through six stages of change (pre-contemplation, contemplation, 
preparation, action, maintenance, and termination) in the process of changing any health-related behavior. There are three other concepts in this model: a) processes of change, referring to different intervention approaches that help people to progress through stages of change, b) self-efficacy, which is the confidence people gain as they progress through the stages, and c) decisional balance, which describes the process of weighing the pros and cons of any health-related behavior. This construct changes as people move through the stages of change. For example, during pre-contemplation, the perceived benefits of not eating FV outweigh the perceived risks. As the person progresses into the action and maintenance stages, the perceptions of the negative consequences of not eating $\mathrm{FV}$ overtake the positive ones (14-17).

In order to develop effective programs, determinants of FV consumption should be recognized. For example, one study in elderly population reported that only $1.5 \%$ of them were in "action" stage for FV consumption in Iran, and the most frequently perceived benefits of and barriers against that were availability and expense, respectively (11). Finding these contributing factors can help to tailor intervention strategies to the target populations and to the most important and best modifiable determinants of behavior (13).

The purpose of this study was to evaluate the situation and determinants of FV intake in Mashhad City based on TTM. To our best knowledge, this is the first population-based study from Mashhad in this regard.

\section{Materials and Methods}

In this cross-sectional study, a total number of 777 participants from Mashhad City, Iran were surveyed in 2014. Mashhad (northeast of Iran) is the second most populous city in the country. It is the capital of Razavi Khorasan Province. Convenience sampling methods were adopted in selecting participants from the general population for this study. For data collection, we referred to public transport stations, public parking lots, car parks of shopping centers, banks, hospitals and universities all around the city. The parking lot of the Holy Shrine of Imam Reza (Eighth Shia Imam) was also a place for data collection. Inclusion criteria were having reading and writing capability, being a citizen of Mashhad City and having consented to participate in the study. Exclusion criterion was being disabled (considered as the loss or limitation of opportunities to take part in society). The sample size was calculated using the proportional FV consumption findings in a similar study about FV consumption in Iran (11). Alfa and Beta errors were considered 0.05 and 0.2 , respectively.

The survey was done using a checklist, and stages of change questionnaire. The checklist consisted of socio-demographic characteristics including age, sex, income, family size, education level, height and weight as well as job status, history of smoking, drug or alcohol abuse, and physical activity (as 30 minutes/day of moderate activity for at least 5 days a week or 20 minutes/day of intense activity for at least 3 days a week).

We used the Persian version of the trans-theoretical model (TTM) questionnaire, being valid and reliable before (11). The questionnaire consisted of six questions with yes and no answers, according to six stages of change. Stages of change refer to a person's readiness to engage in a diet with acceptable amounts of FV. Someone in pre-contemplation stage does not eat $\mathrm{FV}$ and is not planning to start doing so within the next 6 months. A contemplator does not do so but is planning to start within the next 6 months. A person in preparation stage is planning to start adding FV to his/her diet within 1 month and has taken some initial steps toward it. Someone in action stage has been eating $\mathrm{FV}$ in his/her diet for less than 6 months. A person in maintenance stage has been added them in his/her diet for 6 months or more, and finally, the person in termination stage will never leave his/her FV rich diet (18). We asked the participants about their daily FV consumption ( 2 units for fruits and 3 units for vegetables) in the last 2 weeks, and the above TTM categorization was based on this threshold. One unit of fruit was considered as a medium size fruit, half glass of fruits grain, half glass of fresh fruit juice, and a quarter of dried fruits. Each unit of vegetables was considered as one glass of raw vegetables, half of glass for cooked vegetables, half glass of vegetable juice, and a medium size potato. There were 10 and 9 questions for pros of fruit and vegetable consumption, respectively. There were 12 and 14 questions for cons of fruit and vegetable consumption, respectively. The answers were obtained on a 5-point Likert scale from "Not important $=0$ " to "Very important $=5$ ". The validity of this questionnaire was approved by an expert panel, and its reliability was confirmed by Cronbach's alpha of 0.79 (fruit pros), 0.84 (fruit cons), 0.85 (vegetable pros) and 0.87 (vegetable cons).

The interviewers explained the objectives of the research for each participant. They assured them 
about the privacy of their personal data, and after getting oral consent, the questionnaires were filled in through face-to-face interview. Ethics Committee of Mashhad University of Medical Sciences approved the study.

Statistical analyses were done by SPSS 11.5 software (SPSS Inc., Chicago, Illinois, USA) in 2015. Normality of the data was checked with Kolmogorov-Smirnov's test. Standard descriptive statistics (Median and Inter-quartile range) were applied to describe the data. Chi-square test and Mann-Whitney's U test were used to examine the significance of the differences between the groups. Multiple logistic regressions were used to predict the factors influencing on FV consumption. All tests were 2-tailed, and probability values below 0.05 were considered significant.

\section{Results}

The mean age of the study sample was $28.94 \pm 12.95$ years. There were $262(33.8 \%)$ males. More than half of the sample were single (398, $51.2 \%)$. The median family size was 4 with an interquartile range of 3 to 5 .
Twenty patients $(2.5 \%)$ had diabetes, 20 (2.6\%) cardiovascular diseases and $8(1 \%)$ respiratory diseases. Thirty-three (4.2\%) subjects smoked cigars, $40(5.1 \%)$ had a recreational consumption of hookah, and $15(1.9 \%)$ use to drink alcoholic beverages. The median of cigarette smoking was 0.6 pack per year with an inter-quartile range of 0.05 to 6.1 . Other basic characteristics are summarized in Table 1.

The TTM model for fruit consumption revealed that only near a third of the men and women were at termination stage. This was $28.3 \%$ and $21.9 \%$ in vegetable consumption for men and women, respectively (Table 2). After categorizing three initial steps (pre-contemplation, contemplation and preparing) into the FV consumer group, and the latter three steps (action, maintenance, and termination) into the FV non-consumer group, the Chi-square test revealed that there was no significant relation between the stage of TTM in fruit consumption and gender $(\mathrm{p}=0.363)$ and a significant one for vegetable consumption and gender $(\mathrm{p}=0.046)$. Demographic differences between the consumers and nonconsumers are shown in Table 3.

Table 1. Basic characteristics of the study sample

\begin{tabular}{|c|c|c|c|}
\hline & & Male & Female \\
\hline Age (years)** & & $30(22-43)$ & $22(20-31)$ \\
\hline \multirow{2}{*}{ Education* } & Diploma and lower & $116(45)$ & $186(38)$ \\
\hline & Higher than Diploma & $132(55)$ & $304(62)$ \\
\hline \multirow{2}{*}{ Job * } & Employee & $168(72.7)$ & $76(16.6)$ \\
\hline & Unemployed & $63(27.3)$ & $382(83.4)$ \\
\hline Past medical history $*$ & Yes & $35(13.4)$ & $18(6.8)$ \\
\hline Dependency (alcohol or cigar)* & Yes & $52(19.8)$ & $13(2.5)$ \\
\hline Addiction (opium)* & Yes & $6(2.3)$ & $3(0.6)$ \\
\hline Recommended physical activity* & Yes & $134(54.3)$ & $183(37.8)$ \\
\hline Monthly income (Dollars)** & & $400(300-670)$ & $350(270-670)$ \\
\hline $\operatorname{BMI}\left(\mathrm{kg} / \mathrm{m}^{2}\right)^{* *}$ & & $24.7(22.4-27.3)$ & $21.8(19.6-24.5)$ \\
\hline
\end{tabular}

Table 2. Frequency and percentage of participants in each stage of change based on gender and fruit/vegetable consumption

\begin{tabular}{|c|c|c|c|c|}
\hline & \multicolumn{2}{|c|}{ Fruits } & \multicolumn{2}{|c|}{ Vegetables } \\
\hline & $\begin{array}{c}\text { Male } \\
\mathrm{N}(\%)\end{array}$ & $\begin{array}{l}\text { Female } \\
\mathrm{N}(\%)\end{array}$ & $\begin{array}{l}\text { Male } \\
\mathrm{N}(\%)\end{array}$ & $\begin{array}{l}\text { Female } \\
\mathrm{N}(\%)\end{array}$ \\
\hline Pre-contemplation & $34(18.4)$ & $63(18.1)$ & $45(25)$ & $84(26.3)$ \\
\hline Contemplation & $35(18.9)$ & $48(13.8)$ & $33(18.3)$ & $63(19.7)$ \\
\hline Preparing & $14(7.6)$ & $60(17.2)$ & $19(10.6)$ & $55(17.2)$ \\
\hline Non-consumer & $83(44.9)$ & $171(49.1)$ & $97(53.9)$ & $202(63.2)$ \\
\hline Action & $9(4.9)$ & $18(5.2)$ & $10(5.6)$ & $24(7.5)$ \\
\hline Maintenance & $30(16.2)$ & $28(8)$ & $22(12.2)$ & $24(7.5)$ \\
\hline Termination & $63(34.0)$ & $131(37.6)$ & $51(28.3)$ & $70(21.9)$ \\
\hline Consumer & $102(55.1)$ & $177(50.9)$ & $83(46.1)$ & $118(36.8)$ \\
\hline
\end{tabular}


Table 3. Demographic characteristics for fruit/vegetables consumption according to the stages of change of TTM model

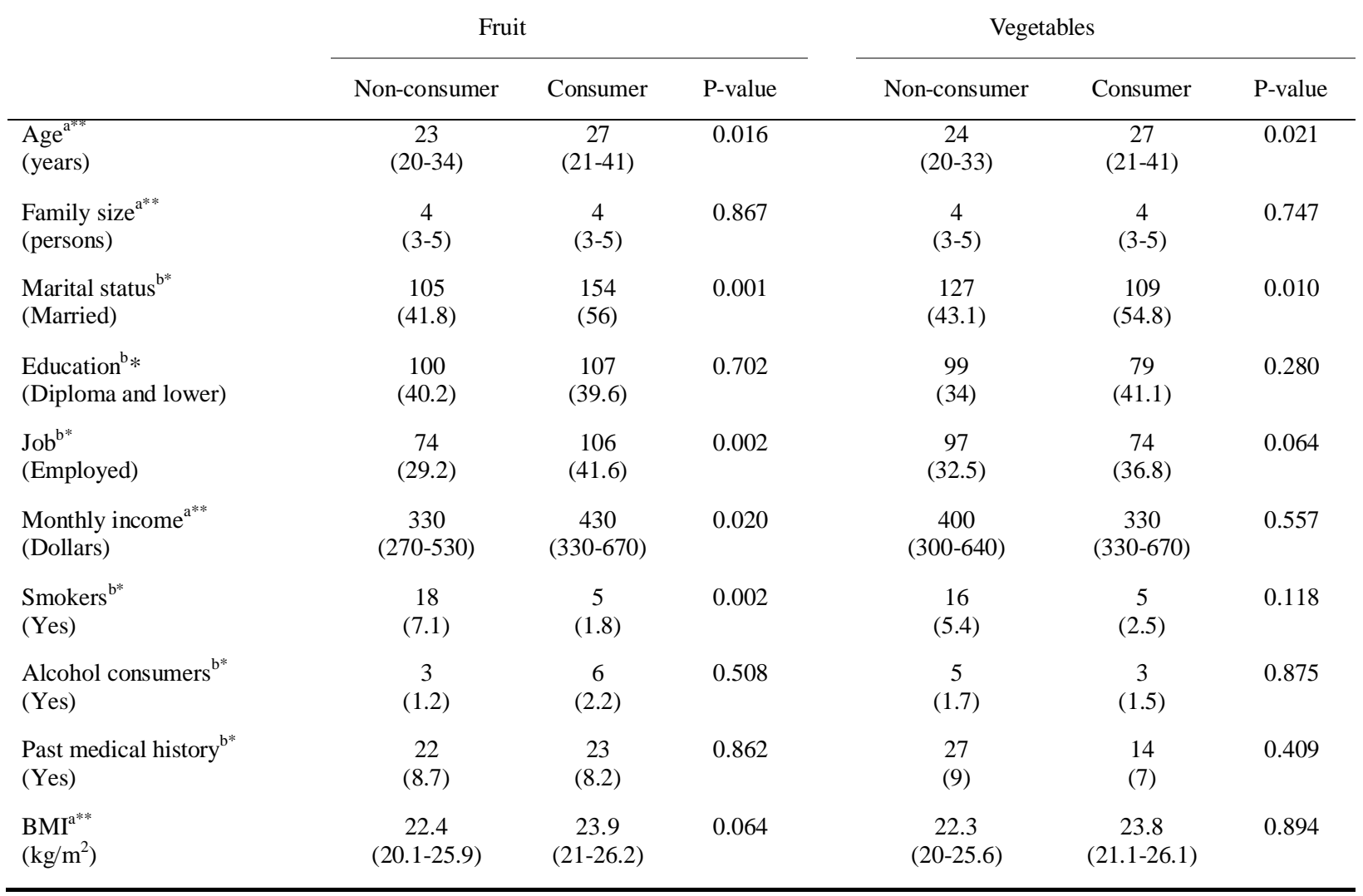

$* \mathrm{~N}(\%)$

$* *$ Median $\left(1^{\text {st }}\right.$ quartile- $3^{\text {rd }}$ quartile $)$.

a Man-Whitney's test was used.

${ }^{\mathrm{b}}$ Chi-square/Fisher Exact test was used.

The highest score for pros of eating fruits was a belief on the potential health benefits of fruits to prevent diseases. This belief was significantly lower in pre-contemplation stage $(\mathrm{p}=0.019)$. However, most of the participants believed that vegetables were good for health. This belief was also significantly lower in pre-contemplation stage $(\mathrm{p}=0.001)$. The least motivation for consuming FV was peer influence, and the participants in pre-contemplation stage had higher scores in both fruit and vegetable consumption (both $\mathrm{p}<0.001$ ). On the other hand, the main obstacle for eating fruit (with a significant difference between precontemplators and others) and vegetables was concern about chemicals used in the processing of them $(\mathrm{p}=0.01$ and $\mathrm{p}=0.17$, respectively). Fortunately, the least important barrier for fruit consumption was time consumption $(\mathrm{p}=0.2)$, and for vegetables, was difficult and time-consuming preparation $(\mathrm{p}=0.4$ and $\mathrm{p}=0.9$, respectively). There was not any significant difference for the pre-contemplation stage (Table 4).

The results of multiple logistic regression test showed that only three variables could significantly predict the possibility of the pre-contemplation stage for fruit consumption including smoking and a couple of pros/cons ( $\mathrm{R}$ Square $=0.06$ ) However, the predictors of termination stage were more $(\mathrm{R}$ Square $=0.11)$ (Table 5). For vegetable consumption, $\mathrm{R}$ Square values for pre-contemplation and termination stage were 0.16 and 0.06 , respectively. Gender was a predictor of termination stage for vegetable consumption (Table 6). 
Veda Vakili \& Majid Khadem-Rezaiyan: Predictors of fruit/vegetable consumption

Table 4. Pros and cons of fruit/vegetable consumption from participants' point of view

\begin{tabular}{|c|c|c|}
\hline & Fruit $($ Mean \pm SD) & Vegetable $($ Mean \pm SD) \\
\hline \multicolumn{3}{|l|}{ Pros } \\
\hline Health benefits for the body. & $4.15 \pm 0.94$ & $4.13 \pm 2.23$ \\
\hline Other people eat this, too. & $3.17 \pm 1.33$ & $3.08 \pm 1.37$ \\
\hline This can substitute for unhealthy food products. & $4.07 \pm 0.95$ & $3.84 \pm 1.07$ \\
\hline It can help one to maintain weight. & $4.10 \pm 1.78$ & $3.91 \pm 1.10$ \\
\hline It can help prevent diseases. & $4.21 \pm 0.91$ & $3.89 \pm 1.14$ \\
\hline It makes me feel better. & $4.03 \pm 1.0$ & $3.71 \pm 1.13$ \\
\hline It makes my diet more varied. & $3.99 \pm 2.03$ & $3.78 \pm 1.07$ \\
\hline It can help one to lose weight. & $3.93 \pm 1.14$ & $3.78 \pm 1.17$ \\
\hline The colorful appearance can increase the appetite & $3.91 \pm 1.06$ & $3.66 \pm 1.22$ \\
\hline My religion has recommended eating this. & $3.91 \pm 1.13$ & - \\
\hline \multicolumn{3}{|l|}{ Cons } \\
\hline Buying this is time-consuming. & $2.14 \pm 1.22$ & $2.30 \pm 1.27$ \\
\hline Eating this is difficult. & $1.91 \pm 1.22$ & $2.10 \pm 1.26$ \\
\hline Eating this is time-consuming. & $1.82 \pm 1.17$ & $2.10 \pm 1.27$ \\
\hline It is hard to find tasty ones. & $2.31 \pm 1.97$ & $2.56 \pm 1.32$ \\
\hline There is a low variation of these in the market. & $2.5 \pm 1.31$ & $2.56 \pm 1.32$ \\
\hline It is hard to keep them. & $2.65 \pm 1.35$ & $3.02 \pm 2.02$ \\
\hline Most of these are tasteless /have bad taste. & $2.59 \pm 1.36$ & $2.70 \pm 1.32$ \\
\hline They are expensive. & $3.33 \pm 1.35$ & $2.62 \pm 1.44$ \\
\hline This spoils quickly. & $3.05 \pm 1.29$ & $3.22 \pm 1.34$ \\
\hline Chemicals on this worry me. & $3.42 \pm 1.41$ & $3.49 \pm 1.34$ \\
\hline It is not routine in my family or society to eat this. & $2.77 \pm 1.41$ & $2.78 \pm 1.32$ \\
\hline There is not adequate advertising to eat this. & $3.04 \pm 1.44$ & $3.0 \pm 1.40$ \\
\hline It takes the time to prepare this. & - & $3.24 \pm 1.40$ \\
\hline It is difficult to prepare this. & - & $3.17 \pm 1.35$ \\
\hline
\end{tabular}

Table 5. Predictors of pre-contemplation and termination stages for fruit consumption among the study participants

\begin{tabular}{|c|c|c|c|c|c|c|}
\hline & $\mathrm{B}$ & S.E. & Wald & $\mathrm{df}$ & Sig. & OR \\
\hline \multicolumn{7}{|l|}{ Pre-contemplation } \\
\hline Smoking* & 1.172 & 0.511 & 5.257 & 1 & 0.022 & 3.227 \\
\hline This is good for the body** & & & 15.581 & 4 & 0.004 & \\
\hline Not at all & -0.808 & 0.728 & 1.232 & 1 & 0.267 & 0.446 \\
\hline Low importance & -1.084 & 0.666 & 2.649 & 1 & 0.104 & 0.338 \\
\hline Moderate importance & -1.492 & 0.607 & 6.045 & 1 & 0.014 & 0.225 \\
\hline Important & -2.052 & 0.620 & 10.952 & 1 & 0.001 & 0.128 \\
\hline Buying this is time-consuming** & & & 9.561 & 4 & 0.049 & \\
\hline Not at all & -0.421 & 0.353 & 1.429 & 1 & 0.232 & 0.656 \\
\hline Low importance & -0.661 & 0.372 & 3.161 & 1 & 0.075 & 0.516 \\
\hline Moderate importance & -1.298 & 0.754 & 2.964 & 1 & 0.085 & 0.273 \\
\hline Important & 0.623 & 0.473 & 1.735 & 1 & 0.188 & 1.865 \\
\hline Constant & -0.211 & 0.590 & .128 & 1 & 0.720 & 0.810 \\
\hline \multicolumn{7}{|l|}{ Termination } \\
\hline This is good for the body** & & & 12.629 & 4 & 0.013 & \\
\hline Not at all & -1.011 & 1.170 & 0.747 & 1 & 0.387 & 0.364 \\
\hline Low importance & 0.230 & 0.956 & 0.058 & 1 & 0.810 & 1.258 \\
\hline Moderate importance & 0.925 & 0.938 & 0.972 & 1 & 0.324 & 2.521 \\
\hline Important & 1.351 & 0.946 & 2.040 & 1 & 0.153 & 3.860 \\
\hline Eating this can help one to maintain weight $* *$ & & & 11.181 & 5 & 0.048 & \\
\hline Not at all & -0.227 & 0.796 & 0.081 & 1 & 0.776 & 0.797 \\
\hline Low importance & -0.916 & 0.701 & 1.709 & 1 & 0.191 & 0.400 \\
\hline Moderate importance & -1.585 & 0.684 & 5.366 & 1 & 0.021 & 0.205 \\
\hline Important & -1.205 & 0.694 & 3.016 & 1 & 0.082 & 0.300 \\
\hline Eating this is time-consuming $* *$ & & & 9.873 & 4 & 0.043 & \\
\hline Not at all & -0.700 & 0.363 & 3.708 & 1 & 0.054 & 0.497 \\
\hline Low importance & 0.312 & 0.337 & 0.857 & 1 & 0.355 & 1.366 \\
\hline Moderate importance & -0.401 & 0.540 & 0.551 & 1 & 0.458 & 0.670 \\
\hline Important & -1.403 & 0.687 & 4.165 & 1 & 0.041 & 0.246 \\
\hline There is low variation of these in market** & & & 12.243 & 4 & 0.016 & \\
\hline Not at all & -0.380 & 0.309 & 1.506 & 1 & 0.220 & 0.684 \\
\hline Low importance & -0.868 & 0.336 & 6.677 & 1 & 0.010 & 0.420 \\
\hline Moderate importance & 0.096 & 0.326 & 0.086 & 1 & 0.769 & 1.100 \\
\hline Important & 0.564 & 0.469 & 1.451 & 1 & 0.228 & 1.759 \\
\hline They are expensive** & & & 13.425 & 4 & 0.009 & \\
\hline Not at all & 0.095 & 0.396 & 0.057 & 1 & 0.811 & 1.099 \\
\hline Low importance & 0.788 & 0.368 & 4.583 & 1 & 0.032 & 2.199 \\
\hline Moderate importance & 0.136 & 0.358 & 0.144 & 1 & 0.704 & 1.146 \\
\hline Important & -0.436 & 0.391 & 1.246 & 1 & 0.264 & 0.647 \\
\hline Constant & -0.625 & 0.918 & 0.464 & 1 & 0.496 & 0.535 \\
\hline
\end{tabular}


Veda Vakili \& Majid Khadem-Rezaiyan: Predictors of Fruit/Vegetable Consumption

Table 6. Predictors of pre-contemplation and termination stages for vegetable consumption among the study participants

\begin{tabular}{|c|c|c|c|c|c|c|}
\hline & $\mathrm{B}$ & S.E. & Wald & $\mathrm{df}$ & Sig. & $\overline{\mathrm{OR}}$ \\
\hline \multicolumn{7}{|l|}{ Pre-contemplation } \\
\hline Physical activity* & 0.696 & 0.263 & 7.001 & 1 & 0.008 & 2.005 \\
\hline This is good for the body** & & & 20.609 & 4 & 0.000 & \\
\hline Not at all & 0.602 & 0.543 & 1.232 & 1 & 0.267 & 1.827 \\
\hline Low importance & 2.135 & 0.479 & 19.867 & 1 & 0.000 & 8.456 \\
\hline Moderate importance & 0.519 & 0.434 & 1.431 & 1 & 0.232 & 1.680 \\
\hline Important & 0.406 & 0.320 & 1.608 & 1 & 0.205 & 1.500 \\
\hline This makes a diet more varied ${ }^{* *}$ & & & 16.322 & 4 & 0.003 & \\
\hline Not at all & 1.186 & 0.577 & 4.233 & 1 & 0.040 & 3.275 \\
\hline Low importance & 1.410 & 0.500 & 7.956 & 1 & 0.005 & 4.095 \\
\hline Moderate importance & 1.290 & 0.411 & 9.846 & 1 & 0.002 & 3.632 \\
\hline Important & 0.397 & 0.397 & 1.000 & 1 & 0.317 & 1.487 \\
\hline Eating this is difficult $* *$ & & & 11.336 & 4 & 0.023 & \\
\hline Not at all & -0.526 & 0.490 & 1.152 & 1 & 0.283 & 0.591 \\
\hline Low importance & -1.634 & 0.600 & 7.407 & 1 & 0.006 & 0.195 \\
\hline Moderate importance & -1.078 & 0.540 & 3.977 & 1 & 0.046 & 0.340 \\
\hline Important & -0.503 & 0.550 & 0.836 & 1 & 0.361 & 0.605 \\
\hline It is difficult to prepare this** & & & 13.785 & 4 & 0.008 & \\
\hline Not at all & -1.331 & 0.446 & 8.906 & 1 & 0.003 & 0.264 \\
\hline Low importance & -1.222 & 0.484 & 6.381 & 1 & 0.012 & 0.295 \\
\hline Moderate importance & -1.195 & 0.390 & 9.408 & 1 & 0.002 & 0.303 \\
\hline Important & -0.905 & 0.346 & 6.839 & 1 & 0.009 & 0.404 \\
\hline Chemicals on this worry me e* $^{* *}$ & & & 10.092 & 4 & 0.039 & \\
\hline Not at all & 0.856 & 0.419 & 4.172 & 1 & 0.041 & 2.355 \\
\hline Low importance & -0.779 & 0.560 & 1.937 & 1 & 0.164 & 0.459 \\
\hline Moderate importance & 0.000 & 0.401 & 0.000 & 1 & 1.000 & 1.000 \\
\hline Important & 0.155 & 0.339 & 0.209 & 1 & 0.648 & 1.168 \\
\hline Constant & -1.701 & 0.545 & 9.752 & 1 & 0.002 & 0.183 \\
\hline \multicolumn{7}{|l|}{ Termination } \\
\hline Gender*** & 0.639 & 0.235 & 7.391 & 1 & 0.007 & 1.894 \\
\hline This makes a diet more varied $* *$ & & & 28.187 & 4 & 0.000 & \\
\hline Not at all & -2.493 & 1.035 & 5.798 & 1 & 0.016 & 0.083 \\
\hline Low importance & -2.405 & 0.750 & 10.269 & 1 & 0.001 & 0.090 \\
\hline Moderate importance & -1.639 & 0.397 & 16.999 & 1 & 0.000 & 0.194 \\
\hline Important & -0.429 & 0.248 & 2.999 & 1 & 0.083 & 0.651 \\
\hline Constant & -1.206 & 0.197 & 37.338 & 1 & 0.000 & 0.300 \\
\hline
\end{tabular}

\section{Disc ussion}

Various health behaviors may contribute to the prevention of non-communicable diseases (19) but the health behavior research mainly focuses on changing single behaviors. We tried to gain insight into two dietary behaviors, i.e. fruit and vegetable intake in Iran. The results showed that men had a better situation for FV intake. Besides, there are many right and wrong beliefs about consuming fruits and vegetables, which knowing them can guide us to target oriented interventions.

The mean age of our sample was near 30, showing that our sample was relatively young. This is confirmed by the status of the marriage, of which more than half are single. Besides, the percentage of males was relatively low which can be related to the study topic. It has been shown that men are less likely to have responsibility for food purchasing and preparation in a patriarchy setting like Iran, and they may, therefore, have a weaker interest in messages or surveys on diet (20).

First of all, only around half of men and women are fruit consumers. This is even worse for vegetable consumption. Other studies have similar (21) or even worse results $(22,23)$. However, we should consider two important points: a) our findings are from a crosssectional study, and b) stage transitions can occur on a short notice, e.g. within three days as it has been shown by a longitudinal study of fruit intake (24). This rapid change can be explained by unreliable stage measurement, real self-change, or the idea that psychological constructs may vary over time (24). 
Married individuals consumed more FV than single ones. This is supported by another study. Marriage support and sharing household chores can be one possible reason (11). Older people had healthier lifestyles regarding FV consumption. This was incongruent with a previously reported study in Iran (11), U.S.A. (25) and France (26) in which the prevalence of low FV consumption tended to increase with age. However, a quasi-experimental study showed that even more improvement in lifestyle (i.e. eating more FV) can be obtained in an elderly population with proper interventions (9). There are not any reports about FV consumption using TTM model regarding stages of change from the developing countries; so, it seems difficult to compare our findings with them.

Different findings have been reported about the relation of gender and FV consumption. We found a significant gender difference for vegetable consumption like the previously reported studies $(26,27)$, and in contrary to another one (11). On the other hand, we did not find any gender difference for fruit consumption, which is similar to one study (11) and in contrary to others $(27,28)$. This can be explained by socio-cultural variations between populations.

Higher income or employment was associated with fruit intake. This finding is similar to other studies $(29,30)$. However, income was not any related to vegetable consumption, unlike the previously mentioned studies. This can be due to low prices of vegetables that make them affordable for most of the people. Also, we suppose that healthy lifestyle may be associated with other health-related behaviors such as smoking, but in this study, only fruit intake was significantly related to the lower frequency of smoking. While two studies had found a significant difference in BMI between consumers and nonconsumers of FV (11,31), this study did not support this finding which can be explained by the method of BMI measurement, calorie intake, and junk foods in diets.

The pros and cons for both fruits and vegetables are somehow similar. The strongest relations between the consumption of fruits and vegetables were reported in former studies. Fruits and vegetables are both recommended on a daily basis, or these are often promoted as a single food group. (20) A negative relationship has been reported between times spent preparing fruit and vegetable meal and the hours working outside the home, regardless of income (32).
However, this relationship was not found in another study (33).

In regression analysis, the most significant variables were factors from pros and cons. This shows the high impact of beliefs for remaining in precontemplation or termination stage. In this study, like two studies in the USA, time and cost were among the most important barriers $(33,34)$. So, public policies that make FV more affordable should be encouraged. It has been shown that $1 \%$ reduction in the price of fruits can lead to a $2 \%$ increase in fruit consumption (35). It is obvious that the cons are of particular importance for relapse, so once people try to change their diets, they may encounter negative experiences with maintaining their new dietary habits. Hence, interventions on changing FV consumption may aim to reduce the importance of negative beliefs arising from behavior change (20). The efficacy of stagetailored nutrition education has been demonstrated in several studies though there were some differences $(9,36,37,38)$. Although some studies have failed to find any significant pros factor for predicting the stages of change $(20,39)$, in the present study, we found that maintaining an ideal weight, being healthy, and inducing a variation in the diet are all among the significant benefits of FV consumption.

We believe that the findings of this study can be used for designing proper interventional programs because each stage needs a specific intervention to move the individuals to a higher one. For example, motivational strategies would be more beneficial for pre-contemplation/contemplation stage while strategies supporting the maintenance would be wiser for individuals in action/maintenance stage (17).

Some limitations of this study must be considered. We performed a convenience sampling method, which can reduce the generalizability of our results. Compared to the Iranian population at large, it seems that in our sample, the respondents with a higher education level, employed, under 40 years of age, and females were over-represented. Although the questionnaire was filled through face-to-face interview, the dropout in the main TTM question in our study can be due to a lack of health literacy of the participants in this domain. However, this was the first population-based study in Mashhad. Recognizing the pros and cons of FV consumption is of high importance for public health managers because they are responsible for the main part of the resistance to change. Targeting these entry points with proper interventions can help people to have a better lifestyle. 
It seems that different factors are responsible for fruit and vegetable consumption. Above all, determining the pros and cons could have a great help to implement the correct public educations or interventions in this regard.

\section{Ac know ledgement}

We appreciate the kind cooperation of Dr. Abbasi in initial steps of performing this study.

\section{Financial disclosure}

The authors declare that they do not have any competing interests.

\section{Funding/Support}

None

\section{References}

1. Koletzko B, de la Guéronnière $\mathrm{V}$, Toschke AM, von Kries R. Nutrition in children and adolescents in Europe: What is the scientific basis? Introduction. Br J Nutr. 2004 Oct; 92 Suppl 2:S67-73.

2. Dosil-Díaz O1, Ruano-Ravina A, Gestal-Otero JJ, Barros-Dios JM. Consumption of fruit and vegetables and risk of lung cancer: A case-control study in Galicia, Spain. Nutrition. 2008 May;24(5):407-13.

3. Dauchet L, Dallongeville J. Fruit and vegetables and cardiovascular disease: Epidemiological evidence from the non-Western world. Br J Nutr. 2008 Feb; 99(2):21920. Epub 2007 Aug 29.

4. Harding AH1, Wareham NJ, Bingham SA, Khaw K, Luben R, Welch A, Forouhi NG. Plasma vitamin C level, fruit and vegetable consumption, and the risk of newonset type 2 diabetes mellitus: The European prospective investigation of cancer--Norfolk prospective study. Arch Intern Med. 2008 Jul 28;168(14):1493-9.

5. He FJ, Nowson CA, Macaregor CA. Fruit and vegetable consumption and stroke: Meta-analysis of cohort studies. Lancet 2006; 367:320-326.

6. Ebrahimi SF, Hoshyarra A, Hossein-Nezhad A, Zandi N, Larijani B, Kimiagar M: Fruit and vegetable intake in postmenopausal women with osteopenia. Arya Atherosclerosis 2006; 1:183-187.

7. DiBello JR, Kraft P, McGarvey ST, Goldberg R, Campos $\mathrm{H}$, Baylin A. Comparison of 3 methods for identifying dietary patterns associated with risk of disease. Am J Epidemiol 2008; 168:1433-1443.

8. International Agency for Research on Cancer (IARC): Handbook of Cancer Prevention Lyon: IARC Press; 2003.

9. Salehi L, Mohammad K, Montazeri A. Fruit and vegetables intake among elderly Iranians: A theory-based interventional study using the five-a day program. Nutr J. 2011 Nov 14;10:123.
10. Riedger ND, Moghadasian MH. Patterns of fruit and vegetable consumption and influence of sex, age and sociodemographic factors among Canadian elderly. Am Coll Nutr 2008; 27:306-313.

11. Salehi L, Eftekhar H, Mohammad K, Tavafian SS, Jazayery A, Montazeri A. Consumption of fruit and vegetables among elderly people: A cross sectional study from Iran. Nutrition Journal 2010 9:2.

12. Sabzghabaee AM, Mirmoghtadaee P, Mohammadi M. Fruit and vegetable consumption among community dwelling elderly in an Iranian population. Int J Prev Med 2010; 1:99-103.

13. Brug J, Oenema A, Ferreira I. Theory, evidence and intervention mapping to improve behavior nutrition and physical activity interventions. Int $\mathbf{J}$ Behav Nutr Phys Act $2005 ; 2: 2$.

14. Alexander GL, McClure JB, Calvi JH, Divine GW, Stopponi MA, Rolnick SJ, et al. A randomized clinical trial evaluating online interventions to improve fruit and vegetable consumption. Am J Public Health. 2010 Feb;100(2):319-26.

15. Horwath CC, Nigg CR, Motl RW, Wong KT, Dishman RK. Investigating fruit and vegetable consumption using the transtheoretical model. Am J Health Promot. 2010 May-Jun;24(5):324-33.

16. Di Noia J, Prochaska JO. Dietary stages of change and decisional balance: A meta-analytic review. Am J Health Behav 2010; 34:618-632.

17. Khadem-Rezaiyan M, Moallem SR, Vakili V. High-risk behaviors while driving: A population-based study from Iran. Traffic Inj Prev. 2016 Jun 3:0. [Epub ahead of print]

18. Prochaska JO, Reddind CA, Ever KE. The Transtheoretical Model and stage of change. In Health Behavior and Health Education, Theory, Research and Practice. Edited by: Glanz K, Rimer BK, Lewis FM. San Francisco: Jossey-Bass; 2008:97-121.

19. Dadgarmoghaddam M, Khajedaluee M, KhademRezaiyan M, Niroumand S, Abrishami M, Joya M, et al. Risk Factors for Non-communicable Disease: A Population Based Study in Mashhad (Iran). BJMMR 2015; 7(6): 503-511.

20. Kristal AR, Hedderson MM, Patterson RE, Neuhauser ML. Predictors of self-initiated, healthful dietary change. J Am Diet Assoc 2001;101:762-766. PubMed PMID: 11478472

21. De Vet E, de Nooijer J, de Vries NK, Brug J. The Transtheoretical model for fruit, vegetable and fish consumption: associations between intakes, stages of change and stage transition determinants. Int $\mathbf{J}$ Behav Nutr Phys Act. 2006 Jun; 19;3:13.

22. Kloek GC, Van Lenthe FJ, Van Nierop PWM, Mackenbach JP. Stages of change for fruit and vegetable consumption in deprived neighborhoods. Health Educ Behav 2004; 31:223-241. 
23. Van Duyn MA, Kristal AR, Dodd K, Campbell MK, Subar AF, Stables G, et al. Association of awareness, intrapersonal and interpersonal factors, and stage of dietary change with fruit and vegetable consumption: A national survey. Am J Health Promot 2001; 16:69-78.

24. De Vet E, De Nooijer J, De Vries NK, Brug J. Stages of Change in fruit intake: A longitudinal examination of stability, stage transitions and transition profiles. Psychol Health 2005;20:415-428.

25. Blanck HM, Gillespie C, Kimmons JE, Seymour JD, Serdula MK. Trends in fruit and vegetable consumption among U.S. men and women, 1994-2005. Prev Chronic Dis. 2008 Apr;5(2):A35. Epub 2008 Mar 15.

26. Tamers SL, Agurs-Collins T, Dodd KW, Nebeling L. US and France adult fruit and vegetable consumption patterns: An international comparison. Eur J Clin Nutr. 2009 Jan;63(1):11-7.

27. Baker AH, Wardle J. Sex differences in fruit and vegetable intake in older adults. Appetite. 2003 Jun;40(3):269-75.

28. Mohammadifar N, Omidvar N, Hoshir Rad A, Maghroom M, Sajjadi F. Dose FV intake differ in adult females and males in Isfahan. ARYA Journal 2006, 1:193-201.

29. Jaime PC, Monteiro CA. Fruit and vegetable intake by Brazilian adults, 2003. Cad Saude Publica. 2005;21 Suppl:19-24. Epub 2006 Jan 31.

30. Smith LT, Johnson DB, Beaudoin S, Monsen ER, LoGerfo JP. Qualitative assessment of participant utilization and satisfaction with the Seattle Senior Farmers' Market Nutrition Pilot Program. Prev Chronic Dis. 2004 Jan;1(1):A06. Epub 2003 Dec 15.

31. Sartorelli DS, Franco LJ, Cardoso MA. High intake of fruits and vegetables predicts weight loss in Brazilian overweight adults. Nutr Res. 2008 Apr;28(4):233-8.
32. Mancino L, Newman C. Who Has Time to Cook? How Family Resources Influence Food Preparation. Washington, DC: Economic Research Service, United States Department of Agriculture; 2007.

33. Hildebrand DA, Betts NM. Assessment of stage of change, decisional balance, self-efficacy, and use of processes of change of low-income parents for increasing servings of fruits and vegetables to preschoolaged children. J Nutr Educ Behav. 2009 MarApr;41(2):110-9.

34. Guenther PM, Dodd KW, Reedy J, Krebs-Smith SM. Most Americans eat much less than recommended amounts of fruits and vegetables. J Am Diet Assoc. 2006Sep;106(9):1371-9.

35. Claro RM1, Carmo HC, Machado FM, Monteiro CA. Income, food prices, and participation of fruit and vegetables in the diet. Rev Saude Publica. 2007 Aug;41(4):557-64.[Article in Portuguese]

36. Greene GW, Fey-Yensan N, Padula C, Rossi SR, Rossi JS, Clark PG. Change in fruit and vegetable intake over 24 months in older adults: Results of the SENIOR project intervention. Gerontologist 2008;48:378-387.

37. Steptoe A, Perkins-Porras L, McKay C, Rink E, Hilton S, Cappuccio FP. Behavioral counseling to increase consumption of fruit and vegetables in low income adults: Randomized trial. BMJ 2003; 326:855.

38. Park A, Nitzke S, Kritsch K, Kattelmann K, White A, Boeckner L, et al. Internet-based interventions have potential to affect short-term mediators and indicators of dietary behavior of young adults. J Nutr Educ Behav. 2008 Sep-Oct;40(5):288-97.

39. De Vet E, De Nooijer J, De Vries NK, Brug J. Determinants of forward stage transition from precontemplation and contemplation for fruit consumption. AJHP 2005;19:278-285. 